\title{
OECD/DAC POVNET 총회 결과
}

개발원조위원회(DAC) 산하 빈곤퇴치 네트워크(POVNET) 전체회의가 2010.3.23-24간 파리 $\mathrm{OECD}$ 본부에서 개최되었다. 금번 회의에서는 MDG 달성 촉진 및 UNGA기여방안, 네트워크 산하 작업반 활동성과 및 향후계획 등을 논의하였다. 동 회의에는 KOICA 정책연구실 변숙진 직원이 참 석하여 아래와 같이 회의 주요 내용을 정리, 보고하였다.

\section{I. 핵심 요지}

$\mathrm{UN}$ 총회(2010.9) MDG 중간평가에 반영될 DAC/POVNET의 MDG 이행 평가 및 POVNET의 역 할에 대한 논의에서 회원국들은 $\mathrm{MDG}$ 가 계속적으로 유효한 프레임워크임을 확인하고, 인적 자본에 의 투자, 식량 안보 등 개발에 대한 균형적 접근의 필요성과 수원국 정부의 역할 및 사회적 보호의 중요성에 합의함. 또한 $\mathrm{DAC}$ 동료심사에 POVNET 빈곤 친화적 성장 등의 주요 이슈가 적극 반영될 수 있도록 건의하기로 함.

2011 12년간 DAC 작업 및 예산 계획(PWB) 관련 POVNET PWB 탬플릿을 점검하고, POVNET 의 비교우위 및 방향 등에 대한 논의가 이루어짐.

\section{II. 주요내용}

\section{가. MDG 이행평가관련 POVNET 역할 및 방향성 논의}

사무국에서는 현시점이 MDG 이행 평가 및 post-2015의 논의를 하기에 적절한 시기라 판단하고, 자원 및 소득의 적절한 분배의 관점을 강조하였음. 또한 원조효과성에 대한 논의시 $\mathrm{DAC}$ 나 $\mathrm{DAC} /$ POVNET의 좁은 범위에서가 아닌 NGOs, 시민사회, 민간섹터로 행위 주체를 확장하는 시각이 필 
요하다고 봄.

\section{나. 이행(Implementation) 태스크팀 활동 보고(2009/10 PWB)}

(빈곤 가이드라인의 동료검토 반영) POVNET 사무국은 POVNET의 주요 성과물인 빈곤감소 가이 드라인 및 빈곤 친화적 성장이 $\mathrm{DAC}$ 동료검토 내용에 영향을 주고 있는 것은 고무적이며, 다음 주 (2010.3.30 예정)에 있을 동료심사 방법론에 대한 DAC 회의에서 더욱 적극적으로 POVNET의 관 점을 반영하기 위해 노력할 것임을 설명함.

(Train4Dev Network) 공여국 합작의 개발 네트워크인 Train4Dev는 OECD DAC POVNET과 공 동으로 빈곤 친화적 성장에 관한 학습행사를 준비해 왔으며, 2010 11년 동안 8개 개도국에서 프 로그램을 진행하기로 계획한 바 있음. 2009년 탄자니아 시범 학습 행사 이후 프로그램 재정비 중이 며, POVNET의 빈곤 친화적 성장을 주제로 농업, 인프라, 무역 섹터에서의 실용적인 정책 도구들 을 공여국 현장 실무자들을 대상으로 소개하는 것을 학습 행사의 내용으로 함. 주제는 국별로 다를 수 있음.

(사회적 보호를 위한 ODA) 사회적 보호(Social Protection) 관련 ODA 통계실적 계상 개선을 위한 회의가 열린 바 있으며(2009.10.21 22), 이러한 노력은 DAC 및 공여주체들이 사회적 보호 관련 $\mathrm{ODA}$ 실적을 체계적으로 집계/평가하여 원조조화를 이루기 위한 것임. 동 회의를 통해 제안된 1) CRS(Creditor Reporting System) 코드의 '사회복지서비스' 영역에 해당되는 자료 검토, 2) 사회 적 보호에 포함될만한 활동 검토, 3) '사회복지서비스'에 추가될만한 다른 범주의 활동들 검토(공여 국의 사회적 보호 관련 지원 활동에 더욱 완성된 관점을 제공하기 위함)에 따라 독일, 호주, $\mathrm{EU}$, 영 국은 시범적으로, 사회적 보호 $\mathrm{ODA}$ 측정 및 모니터링에 대한 자국의 접근 방식을 질의응답의 형태 로 공개하였음. 질문은 1) 사회적 보호 관련 $\mathrm{ODA}$ 정책을 가지고 있는가, 2) 사회적 보호를 어떻게 정의하는가, 3) 사회적 보호를 위한 $\mathrm{ODA}$ 를 어떻게 측정하고 있는가 (관련 목적코드를 만들었는가) 등으로 구성되어 있음.

(중국-DAC 스터디 그룹) 2009년 1월, International Poverty Reduction Center in China(IPRCC)의 제안으로 설립된 중국-DAC 스터디 그룹은 중국과 아프리카에서 빈곤감소와 성 장 개선에 관한 경험을 교환하고 정보를 종합하여 국제적인 플랫폼을 제공하기 위한 목적을 가짐. 동 스터디 그룹은 POVNET이 발전시켜온 정책 가이던스를 따라 1) 농업, 식량 안보 및 농촌 개발, 2) 인프라, 3) 기업을 육성하는 환경 만들기라는 3가지 주제에 집중하고 있음. 동 회의에서는 아프 리카가 중국의 경제 목표와 활동을 채택하는 전략을 핵심 주제로 토론하였음. 중국에서 기업 부문 
의 활성화가 중요한 역할을 했으며, 마찬가지로 중국 기업이 아프리카에서도 중요한 역할을 담당하 기 시작한 것에 동의함. 아프리카 내 중국의 역동적인 경제활동은 환영 할 만하나, 아프리카 국가들 이 개발협력 정책 대화 및 행동에 중국이 참여하는 것에 대한 찬반 토론이 이루어졌음. 다만, 중국 은 아프리카 대륙에 큰 관심을 가지고 있으며 다른 공여기관들에 새로운 영향을 주고 있는 것은 분 명함을 확인함.

\section{다. 역량강화(Empowerment) 태스크팀 활동 보고(2009/10 PWB)}

(GOVNET과 합동 세미나 준비) 빈곤 친화적 성장, 인권, 젠더 부문에서의 잠재적인 시너지 효과를 어떻게 활용할 것인지에 대한 관심이 커지고 있고, 최근 빈곤 친화적 성장과 인권의 결합을 통한 개 발 기회를 확인한 연구가 이루어졌으며, 더 큰 개발 성과를 위해 공동의 접근이 가능한 분야에 대한 연구가 필요하다는데 의견을 공유함.

GOVNET 사무국은 실무적인 단계에서 시너지를 얻을 수 있는 공동의 역량강화 주제를 찾는 것이 중요하고, 함께 논의하는 자리가 처음인 만큼 의미 있는 작업일 것이라고 평가함. 탄자니아는 최빈 곤층의 관점과 현실을 잘 반영하는 것이 가장 중요하다고 재차 강조하였으며, EU, GENDERNET 을 비롯하여 대다수 참가국들은 거버넌스의 역할이 $\mathrm{MDG}$ 이행에 중요성을 가지며, 공동 노력의 시 점으로 현재가 매우 적합하다는 것에 동의함.

\section{라. 2011 12년간 POVNET PWB 탬플릿 검토}

사무국에서 $\mathrm{DAC}$ 회의(2010.3.16)에서 도출된 향후 2 4년간의 DAC 작업 이슈 및 방향에 대해 설 명하고, '경제 성장 및 정책' (예산계획 $\mathrm{IV}$ 에 해당)에 포함된 POVNET의 주요 의제인 녹색 성장과 빈곤, 지구적 식량 안보, 사회적 보호의 내용을 중심으로 회원국들의 의견을 공유함. 


\section{III. 관찰 및 건의}

(DAC 회원국으로서 국제규범 적용 노력 필요) 국제원조규범을 형성하고 모니터링을 총괄하고 있 는 $\mathrm{OECD} / \mathrm{DAC}$ 에 가입함으로써, $\mathrm{KOICA}$ 는 국제규범에 부응하는 선진화된 원조 체계 수립을 위해 $\mathrm{DAC}$ 산하 작업반 규범 적용을 확대하는 것이 바람직함. 특히, $\mathrm{DAC} / \mathrm{POVNET}$ 은 빈곤 친화적 성장 가이드라인을 동료평가에 적극 반영하려는 노력을 기울이고 있는 바, $\mathrm{KOICA}$ 는 향후 동료평가에 대 비하여 동 가이드라인 숙지 및 관련 지침 마련에 노력을 기울여야 할 것으로 판단됨.

(KOICA 정책과 빈곤 이슈의 연계성 강화) DAC 회원국을 포함한 각 공여주체들은 2010년 9월 UN 총회의 $\mathrm{MDG}$ 이행평가에 대비하여 자국의 $\mathrm{MDG}$ 이행 가속화 및 성과 제고를 위해 노력하고 있는 것으로 관찰됨. $\mathrm{KOICA}$ 는 올해 정책이슈별 연구과제의 하나로 빈곤영향평가 가이드라인 수립을 목 표로 설정한 바, 국제사회 내 MDG 1 (절대빈곤 및 기아퇴치) 목표의 중요성이 거듭 강조되고 있음 을 주목하여, MDG 1과 긴밀하게 연결되어 있는 POVNET 핵심 논의 내용들(사회적보호 구축 및 녹색성장)을 follow-up 하고, 관련 KOICA 정책 및 전략 마련에 힘써야 할 것으로 판단됨.

(KOICA 무상원조사업의 가시성(visibility) 제고) POVNET 산하 태스크팀에서 활발히 진행하고 있 는 역량강화 활동 모범사례 수집에 KOICA 무상원조사업의 성공 사례를 반영하려는 노력을 기울일 필요가 있음. 빈곤층을 위한 성장을 위해 중요한 농업 및 인프라 분야의 경우, 우리의 개발경험을 적용할 수 있는 분야라 할 수 있으므로 동 POVNET 역량강화 활동에 참여함으로써 우리의 MDG 이행노력 및 성과에 대한 홍보 효과를 기대할 수 있을 것으로 판단됨. 더 나아가, $\mathrm{KOICA}$ 를 중심으 로 하는 한국의 무상원조사업을 국제사회의 공감을 얻을 수 있는 방향으로 재정비하는 계기가 될 수 있을 것임. 